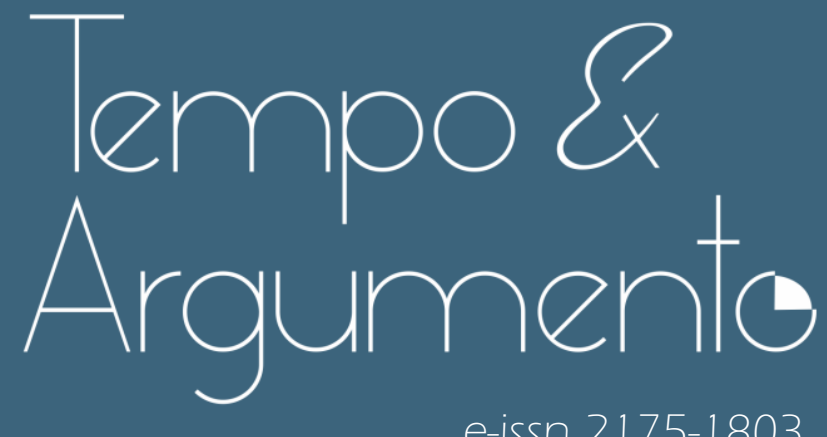

e-issn 2175-1803

\title{
A imaginação nacional dos judeus norte-americanos: do pluralismo cultural liberal e sionista de Horace Kallen às incertezas do século XXI
}

\& Flávio Limoncic

Doutor em História pela Universidade Federal do Rio de Janeiro (UFRJ).

Professor do Departamento de História, do Programa de Pós-Graduação em

História e do Mestrado Profissional em História da Universidade Federal do

Estado do Rio de Janeiro (UNIRIO).

Rio de Janeiro, RJ - BRASIL

lattes.cnpq.br/4578264607538661

limoncic@gmail.com

(D) orcid.org/0000-0002-2317-7349

Para citar este artigo:

LIMONCIC, Flávio. A imaginação nacional dos judeus norte-americanos: do pluralismo cultural liberal e sionista de Horace Kallen às incertezas do século XXI. Tempo e Argumento, Florianópolis, v. 13, n. 33, e0202, maio/ago. 2021.

doi)

http://dx.doi.org/10.5965/2175180313332021 e0202

Recebido: 12/03/2020

Aprovado: 19/02/2021 


\title{
A imaginação nacional dos judeus norte-americanos: do pluralismo cultural liberal e sionista de Horace Kallen às incertezas do século XXI
}

\begin{abstract}
Resumo
No debate de inícios do século XX acerca da incorporação dos imigrantes europeus, duas perspectivas compartilhavam a visão de que a nação norte-americana se assentava sobre valores cívicos, mas divergiam quanto às formas da incorporação: de um lado, o melting-pot de Israel Zangwill; de outro, o pluralismo cultural de Horace Kallen. Ao elaborar a ideia de pluralismo cultural, Kallen propôs, ademais, que os judeus dos Estados Unidos construíssem sua identidade norte-americana articulando sionismo e liberalismo. No pós-Segunda Guerra Mundial, os judeus dos Estados Unidos teriam, portanto, construído uma imaginação nacional assentada nesses dois eixos culturais e políticos. Desde os anos 1970, porém, o consenso sionista dos judeus norte-americanos entrou em processo de erosão, o que, ao lado de mudanças demográficas, tem colocado novos desafios à sua imaginação nacional neste início de século XXI.
\end{abstract}

Palavras-chave: Estados Unidos. Sionismo. Liberalismo. Pluralismo cultural. Horace Kallen.

\section{The national imagination of American Jews: from the liberal and Zionist cultural pluralism of Horace Kallen to the uncertainties of the 21st century}

\begin{abstract}
In the early 20th century debate about the incorporation of European immigrants, two perspectives shared the view that the American nation was based on civic values, but differed on the forms of incorporation: on the one hand, Israel Zangwill's melting-pot; on the other, Horace Kallen's cultural pluralism. When developing his idea, Kallen proposed, in addition, that the Jews of the United States should construct their American identity articulating Zionism and liberalism. After World War II, Jews in the United States would, therefore, have built a national imagination based on these two cultural and political axes. Since the 1970s, however, the Zionist consensus of American Jews has eroded, which, along with demographic chances, brings new challenges to their national imagination at the beginning of the 21st century.
\end{abstract}

Keywords: Estados Unidos. Sionismo. Liberalismo. Pluralismo cultural. Horace Kallen. 
A imaginação nacional dos judeus norte-americanos: do pluralismo cultural liberal e sionista de Horace Kallen às incertezas do século XXI

Flávio Limoncic

\section{Liberalismo e imaginação nacional dos judeus norte-americanos}

Em 1896, Adolph Ochs, filho de imigrantes judeus alemães, tornou-se proprietário do The New York Times e fez dele um dos mais importantes jornais dos Estados Unidos. ${ }^{1}$ No pós-Segunda Guerra, filhos e netos de judeus de origem russa, polonesa, romena e húngara entraram em números crescentes nas universidades e ascenderam às classes médias profissionais. Na década de 1960, os judeus se encontravam a tal ponto integrados à sociedade norte-americana perfaziam, por exemplo, 20\% dos professores das universidades de elite - que Will Herberg (1960) chegou a afirmar serem os Estados Unidos um país protestante, católico e judeu, muito embora judeus nunca houvessem superado a marca de $4 \%$ da população do país. Com quase $40 \%$ dos judeus do mundo, os Estados Unidos abrigam hoje a maior população judaica fora do Estado de Israel e, certamente, a mais influente e afluente do mundo (GINSBERG, 1993). Não admira, pois, que seus recursos econômicos, políticos e culturais tenham sido associados por Edward Said (2003) ao consistente apoio proporcionado por sucessivos presidentes norte-americanos a governos israelenses. Walt e Mearsheimer (2007) chegaram a afirmar ser o chamado lobby de Israel um risco para os interesses dos Estados Unidos.

No entanto, já em 1986, Steven Cohen sugeria que jovens judeus norteamericanos estavam se afastando do grande consenso sionista - cujo ápice se deu entre as Guerras dos Seis Dias, em 1967, e do Yom Kippur, em 1973 - de seus pais e avós. Em 1995, pesquisa de opinião do American Jewish Committee (AJC) mostrou que $37 \%$ dos judeus norte-americanos maiores de 60 anos se declararam fortemente ligados a Israel, contra 22\% daqueles de até 39 (COHEN, 1986; MARKET FACTS, 1995).

Para Steven Rosenthal (2001), a vitória do partido Likud nas eleições israelenses de 1977 foi decisiva para a inflexão da atitude dos judeus norteamericanos em relação a Israel. Sob governos dos herdeiros do sionismo

\footnotetext{
' O presente artigo contou com o apoio do CNPq, através do projeto "Conflito, conciliação, império e humanismo: quatro abordagens da questão nacional no mundo contemporâneo”, coordenado pela professora Denise Rollemberg (Departamento de História da UFF). O autor agradece os comentários e sugestões de dois pareceristas anônimos que contribuíram para eliminar imprecisões, acrescentar reflexões e tornar o texto mais claro.
} 
A imaginação nacional dos judeus norte-americanos: do pluralismo cultural liberal e sionista de Horace Kallen às incertezas do século XXI

Flávio Limoncic

revisionista de Vladimir Jabotinksi, Israel conduziu a Guerra do Líbano, palco do Massacre de Sabra e Chatila, em 1982, e colonizou a Cisjordânia, ensejando a primeira intifada palestina, em 1987. Diante de tal cenário, judeus marcados pela tradição liberal norte-americana teriam assumido posturas mais críticas a Israel, tendência aprofundada após o assassinato de Itzhak Rabin, em 1995, e o fracasso dos Acordos de Oslo.

Os judeus dos Estados Unidos são associados ao liberalismo norteamericano desde a Era Progressista, em princípios do século XX. Foi então que, frente à incapacidade do liberalismo clássico em reproduzir uma sociedade liberal - ou seja, diante da transformação do livre mercado em mercado oligopolizado em setores como a indústria química, a produção de aço e as ferrovias - o liberalismo norte-americano passou a atribuir ao Estado o papel de regulador dos mercados, de modo a resguardar a concorrência. Para fortalecer a autonomia do indivíduo diante das incertezas econômicas e ampliar a margem da liberdade individual, a partir de 1933 o liberalismo do New Deal também passou a defender a construção de redes de segurança social e a não interferência do Estado em hábitos e condutas dos cidadãos (GERSTLE, 1994; LIMONCIC, 2010).

Opiniões sobre temas da agenda política doméstica confirmam tal associação: em 2013, mais de 70\% dos judeus dos Estados Unidos eram favoráveis ao casamento de pessoas do mesmo sexo, contra 55\% na média nacional de três anos depois. Em 2018, 46\% se declararam favoráveis ao aumento da imigração, sendo 17\% contrários, e 70\% defendiam o controle de armas. Como desdobramento, 61\% votaram em Hillary Clinton em 2016, contra 17\% em Donald Trump (AMERICAN JEWISH COMMITEE, 2013, 2016, 2018a, 2019).

A votação em Clinton evidencia a ligação entre judeus e Partido Democrata que remonta ao New Deal. Em 2019, 53\% dos judeus dos Estados Unidos eram democratas, contra 14\% de republicanos. No mesmo ano, o Senado contava com nove judeus democratas e nenhum republicano, e na Câmara havia 18 judeus democratas e um republicano. Os únicos segmentos da sociedade que votam no Partido Democrata em proporções equivalentes às dos judeus, ou seja, 20\% acima da média nacional, são os negros, os pobres e os desempregados. Os 
A imaginação nacional dos judeus norte-americanos: do pluralismo cultural liberal e sionista de Horace Kallen às incertezas do século XXI

Flávio Limoncic

judeus constituem, portanto, caso atípico de dissociação entre mobilidade social ascendente no pós-Segunda Guerra e fidelidade ao partido do New Deal e à reforma social. Ainda que com tensões e contradições, os judeus tiveram, por exemplo, forte atuação nas grandes jornadas pelos direitos civis dos anos 1950 e 1960. Cerca de $2 / 3$ dos brancos que participaram do Verão da Liberdade no Mississippi, em 1964, eram judeus. Dentre eles, Michael Schwerner e Andrew Goodman, cujos assassinatos foram retratados no filme Mississippi em Chamas, de Alan Parker. Não à toa, Milton Himmelfarb afirmou que os judeus dos Estados Unidos ganham como episcopais, mas votam como porto-riquenhos (AMERICANISRAELI COOPERATIVE ENTERPRISE, c2020a; BERGER, 2006; GINSBERG, 1993; MOORE, 1981).

Isso não significa dizer que judeus não tenham vocalizado outras tradições políticas. Jonathan Sarna (1999) mostra como, ao longo do período colonial, judeus alinhavam-se a tradições conservadoras e, na Guerra Civil, lutaram em ambos os lados (SARNA; MANDELSOHN, 2010). No século XX, intelectuais como Leo Strauss deram contribuições fundamentais ao pensamento conservador (TARCOV, 2016) e Ayn Rand $(1943,1957)$ tornou-se best-seller. Não menos importante, Norman Podhoretz e William Kristol foram protagonistas do neoconservadorismo e Paul Wolfowitz e Elliot Abrams participaram da formulação da política externa do governo George W. Bush. Em 2018, Paul Gottfried, um dos expoentes do libertarianismo, achou necessário vir a público para negar ser padrinho político de neonazistas da alt-right (GOTTFRIED, 2018).

Ainda assim, o Partido Democrata teve, e continua tendo, apoio sustentado dos judeus dos Estados Unidos e o liberalismo continua sendo a tradição política com a qual eles preferencialmente se identificam. Diante de tal quadro, uma questão se impõe: por que razão, ou razões, o liberalismo se tornou elemento tão importante da vida judaica norte-americana?

A pergunta não é nova, tampouco as respostas aventadas. Já em 1956, Lawrence Fuchs (1980) identificou na tradição judaica da justiça social, na autonomia intelectual advinda do estudo da Torá e no fato de o judaísmo afirmar a ação no mundo os elementos explicativos do liberalismo judaico. Irving Howe (2006), por seu lado, entendia o liberalismo como legado do socialismo das 
gerações dos imigrantes. Explicações de corte sociológico também foram elaboradas, com destaque para a de Steven Cohen (1989), que enfatizava a ascensão social dos judeus como profissionais liberais altamente educados, voltados, portanto, para valores difusos de justiça social, e a de Charles Liebman (1973), para quem a adesão dos judeus aos valores universais do liberalismo teriam como objetivo minar as restrições a eles impostas pelos grupos política e socialmente dominantes.

Se as interpretações de Cohen e Liebman contribuem para a compreensão do fenômeno, o liberalismo na vida judaica norte-americana também pode ser atribuído ao fato de ter ele se tornado elemento da própria imaginação nacional dos judeus dos Estados Unidos.

Horace Kallen foi um dos proponentes intelectuais da aproximação entre os judeus norte-americanos e o liberalismo. Nascido em Berenstadt, Silésia (então Alemanha, hoje Polônia), em 1882, Kallen chegou aos Estados Unidos em 1887. Na casa paterna, viveu sob as rígidas - e, para ele, sem sentido - regras do judaísmo ortodoxo. Na escola pública, descobriu a enormidade da América. Adulto, propôs o conceito de pluralismo cultural e associou o liberalismo ao sionismo (SCHMIDT, 1995).

\section{Theodor Herzl e o sionismo europeu}

Os anos em que Kallen estava na escola pública norte-americana foram aqueles em que a imaginação nacional judaica europeia tomou a forma do sionismo político de Theodor Herzl.

O advento do mundo moderno lançou uma série de desafios aos judeus europeus, tanto no que se refere à construção de novas subjetividades quanto no que diz respeito às relações a serem estabelecidas com as nações e EstadosNação que então se constituíam. Deveriam eles permanecer fiéis ao seu modo de vida tradicional, ao preço de se apartarem dos novos direitos, deveres, identidades e lealdades que se construíam no âmbito dos Estados-Nação, ou incorporar-se a tais Estados e sociedades nacionais, ao preço de se afastarem 
A imaginação nacional dos judeus norte-americanos: do pluralismo cultural liberal e sionista de Horace Kallen às incertezas do século XXI

Flávio Limoncic

de seu modo de vida tradicional? Por outro lado, tais sociedades e Estados-Nação estavam efetivamente dispostos a incorporá-los? (BAUMAN, 1988).

As respostas dadas foram diferenciadas porque múltiplas foram as formas como o mundo moderno sobre eles incidiu, como o experimentaram e como com ele negociaram. Em dezembro de 1789, por exemplo, quando a Assembleia Nacional Francesa debateu se os direitos do homem e do cidadão deveriam ser estendidos aos judeus, não houve consenso sequer entre eles próprios. Como resultado, em janeiro de 1790, somente judeus com nomes portugueses e espanhóis, assim como os que residiam em Avignon, receberam cidadania plena. Asquenazitas foram obrigados a esperar quase dois anos para se tornarem cidadãos franceses (SORKIN, 2010, p. 180).

Não por acaso, a Revolução Francesa marca simbolicamente o início do que François Hartog (2017, p. 19) chama de moderno regime de historicidade, ou seja, uma percepção do tempo voltada para o futuro. Se muitos judeus - e não judeus - do século XIX abraçaram esse regime, outros permaneceram imersos no regime antigo; uma percepção do tempo voltada para o passado. Os que sentiram o novo regime como uma ampliação do seu horizonte de expectativas (KOSELLECK, 2015), abraçaram as novas identidades nacionais na França, Alemanha, Áustria-Hungria e Inglaterra, muitos chegando a se converter ao cristianismo - Benjamin Disraeli, judeu sefaradita que se tornou primeiroministro da Grã-Bretanha, talvez seja o exemplo mais conhecido. Já os que o sentiram como uma ameaça ao seu campo de experiência, elaboraram as diversas formas da ortodoxia judaica (HEILMAN, 2006, p. 2). Houve, ainda, os que articularam ampliação do horizonte de expectativa e apego ao campo de experiência, seguindo os passos de Moses Mendelsohn (1729-1786). Buscando conciliar judaísmo e mundo moderno, muitos judeus alemães, por exemplo, abraçaram a Reforma judaica e a Bildung, a busca da realização pessoal - e da distinção social - pelo cultivo da educação e adesão à cultura alemã (MENDESFLOHR, 1999). No Império Russo, que até a Revolução de 1917 possuía traços de Antigo Regime, judeus deram os primeiros passos do que poderia vir a ser uma identidade cultural judaica laica e ídiche e aderiram ao partido socialista Algemeiner Yidisher Arbeter Bund in Lite, Poylin und Russland, ao passo que 
A imaginação nacional dos judeus norte-americanos: do pluralismo cultural liberal e sionista de Horace Kallen às incertezas do século XXI

Flávio Limoncic

outros aderiram ao sionismo de Asher Ginsberg (Ahad Ha'am), para quem a Palestina deveria ser um centro irradiador da cultura judaica. O sionismo político de Theodor Herzl foi outra das respostas dos judeus europeus à modernidade: ao enfatizar a rejeição das novas sociedades nacionais aos judeus, o sionismo concebeu-os, eles próprios, como uma nação à moda europeia (GITELMAN, 2003; MINCZELES, 1995).

Para Herzl (1904), o século XIX teria testemunhado o ocaso do tradicional preconceito antijudaico, de cunho religioso e econômico-social, e visto surgir um tipo novo, resultado das contradic,ões do processo de emancipac,ão dos judeus em diferentes países europeus. Consequentemente, a chamada Questão Judaica só poderia ser encaminhada através de uma solucãa moderna: um Estado nacional em que os judeus constituíssem o coração da cidadania e da identidade nacional. Tal solução logo entraria em choque com a tradicional noção judaica de Galut, o exílio diaspórico. Para as correntes do judaísmo ortodoxo, a Galut representava a punição divina aos judeus por sua incapacidade de se manterem à altura das exigências do Pacto. Mais do que um exílio de Sion, a Galut representava o silêncio de Deus - o desencantamento do mundo, na visão weberiana (PIERUCCI, 2013, p. 73) -, só passível de ser superado no momento em que este enviasse à Terra o seu Messias. Para o sionismo, ao contrário, o exílio evidenciava a anomalia da nação judaica, fruto da erosão da vontade nacional dos próprios judeus. Joseph Roth (2016, p. 51-52) bem sintetizou a tensão entre judaísmo ortodoxo e sionismo ao afirmar que "entre a ortodoxia e um sionismo que constrói estradas durante o shabat não pode haver reconciliação". Herzl viase às voltas, portanto, com o desafio de emancipar os judeus da própria religião judaica. Max Nordau (1884), o primeiro intelectual de prestígio a aderir ao sionismo herzliano, chegara a afirmar que o judaísmo esposava uma concepc,ão infantil do universo e uma moralidade revoltante.

Do ponto de vista teórico, o sionismo herzliano poderia ser pensado tanto a partir da contribuição de Anthony Smith (2003), para quem as nações - a judaica, inclusive - constituem fenômenos da longa duração, como a de Shlomo Sand (2009), para quem a nação judaica resultaria de uma invenção moderna do próprio sionismo. Na primeira, a antiga vontade nacional, embora erodida, seria 
passível de recomposição. Na segunda, o conceito de Am Yisrael, o Povo de Israel, teria sido transmutado em nação judaica.

Nem longa duração, nem invenção. Benedict Anderson (2008) permite pensar o Povo de Israel e a nação judaica como dois estilos distintos de imaginação comunitária; o primeiro centrado na tradição do Pacto, o segundo, produzido nos marcos da difusão das línguas vernáculas (no caso, na vernaculização do hebraico), das múltiplas respostas dos judeus ao advento do mundo moderno e da erosão dos Impérios Austro-Húngaro e Russo. Para retomar Hartog e Koselleck, judeus ortodoxos e sionistas viveriam em regimes de historicidade distintos, por distintas serem suas leituras da experiência e da expectativa. Para os primeiros, a expectativa seria o advento da Era Messiânica, resultado da relação de um povo com seu deus; para os segundos, o Estado Judaico, expressão da relação de um povo com sua terra.

\section{Horace Kallen e o pluralismo cultural}

Os anos em que Kallen estava na escola foram, também, aqueles em que conflitos em torno da imaginação nacional norte-americana conheceram momentos de grande tensão.

De um lado, a Guerra Civil e as Emendas da Reconstrução (13ª , de 1865, abolindo a escravidão; 14ª , de 1868, criando uma cidadania nacional e estabelecendo a igual proteção da lei; $15^{\mathrm{a}}$, de 1870, afirmando que o direito ao voto não poderia ser a ninguém negado por motivo de raça, cor ou condição prévia de cativeiro) traziam os ex-escravizados e seus descendentes para o centro do debate nacional; de outro, entre meados do século XIX e 1924, cerca de 34 milhões de imigrantes entraram nos Estados Unidos. Católicos, judeus e cristãos ortodoxos, latinos, eslavos e magiares, tais imigrantes se dirigiram, sobretudo, às grandes cidades do Meio-Oeste e da Costa Leste, como Chicago e Nova York. No dizer de Franz Boas (1909), ele próprio judeu nascido na Alemanha, os Estados Unidos constituíam caso único de encontro de diferentes tradições religiosas e troncos etnolinguísticos, não apenas pelo ritmo e amplitude da imigração, mas por tal encontro ter se dado no espaço urbano, tornando mais 
A imaginação nacional dos judeus norte-americanos: do pluralismo cultural liberal e sionista de Horace Kallen às incertezas do século XXI

Flávio Limoncic

visíveis e sensíveis as diferenças, as interações e os conflitos (DAHL, 2003, p. 1549).

Para utilizar a conceituação de Hans Kohn (1961), a Emancipação e a imigração ensejaram a construção de dois estilos de imaginação nacional norteamericana: de um lado, o que enfatizava sua dimensão racial; de outro, o que enfatizava sua dimensão cívica.

Como o pensamento racialista do século XIX tornava indistintos fenômenos de natureza biológica e cultural, os defensores do estilo racial entendiam a nação norte-americana não apenas como anglo-saxã, mas também protestante. Na guerra de 1846-1848 contra o México, os mexicanos eram entendidos como racialmente inferiores tanto por serem mestiços quanto por serem católicos. Católicos e judeus, assim como latinos, magiares, eslavos e semitas, para não falar dos ex-escravizados e seus descendentes, estavam, portanto, fora da comunidade imaginada de partidos como o Native American Party (cujos militantes eram conhecidos como know-nothing); de grupos vigilantistas, como a Ku Klux Klan (KKK), criada para combater a Reconstrução e ressurgida em 1915 com agenda anticatólica e antissemita; e de organizações como a Immigration Restriction League, que associavam os processos migratórios ao suicídio racial (GUARDINO, 2017; HIGHAM, 1965).

Ainda na segunda metade do século XIX, no entanto, as teses da fronteira, como as de Theodore Roosevelt (1900) e Frederick Turner (1962), introduziram a ideia de que a nação norte-americana não constituía matéria propriamente de sangue ou religião, mas que se forjara na pradaria, na experiência compartilhada da conquista do Oeste. As ideias de que todos os homens nascem livres e iguais e têm direito à busca da felicidade, de que o governo é fruto de um contrato entre governantes e governados, de que o indivíduo é a matriz básica de organização da sociedade e de que o espírito americano não conhece fronteiras, tão caras ao excepcionalismo norte-americano, abriam a possibilidade para que todos os que compartilhassem tais valores cívicos se tornassem americanos (GERSTLE, 2011).

As concepções raciais de nação condenavam os imigrantes judeus ao papel de outsiders. Para se tornarem established, não lhes restava alternativa a 
A imaginação nacional dos judeus norte-americanos: do pluralismo cultural liberal e sionista de Horace Kallen às incertezas do século XXI

Flávio Limoncic

não ser contribuir para a construção de uma comunidade imaginada nacional baseada em valores cívicos (ELIAS; SCOTSON, 2000). Israel Zangwill e Horace Kallen foram particularmente importantes para tal construção, ainda que propusessem diferentes estilos de imaginação.

A ideia do melting-pot, provavelmente cunhada por Jean de Crèvecoeur, em 1782, tornou-se crescentemente popular com a peça The melting-pot, de Israel Zangwill (1919). Encenada pela primeira vez em 1908, a peça apresenta a trajetória de David Quixano, judeu sobrevivente de um pogrom russo que, nos Estados Unidos, casa-se com Vera Revendal, filha do oficial russo que supervisionou o massacre de sua família. A mensagem: o Novo Mundo dissolve os ódios do Velho, a América é o lócus onde os muitos se tornam um.

Kallen percebia o melting-pot como um risco à democracia, dado que só poderia resultar da imposição de padrões culturais uniformes a uma população etnicamente heterogênea. Por isso, propunha, pelo contrário, que os diversos grupos étnicos presentes nos Estados Unidos preservassem suas características fundamentais. Assim como cada instrumento de uma orquestra possui timbre próprio, também cada grupo de imigrantes contribuiria para o som harmônico da nação norte-americana. Kallen (1998) chegou a chamar a atenção para o fato de que o próprio nome do país, Estados Unidos da América, vinculava-o, por um lado, a uma experiência histórica contratual - a vontade de união de 13 colônias - e, por outro, desvinculava-o de qualquer filiação étnica particular, ao contrário da França, o país dos francos, ou da Rússia, o país dos russos. No entanto, ao restringir seu pluralismo cultural aos imigrantes europeus, Kallen contribuiu a um só tempo para embranquecer os judeus e não incorporar os afro-americanos à sinfonia norte-americana (JACOBSON, 1998; LIPSET; RAAB, 1995, p. 33).

O pluralismo cultural de Kallen era parte do processo mais amplo de redefinição do liberalismo norte-americano. Em The promise of American life, de 1909, Herbert Croly (1989) afirmava que o acirramento do conflito social então vivido evidenciava a incapacidade do individualismo de produzir coesão social e propunha a organização da sociedade em grupos de interesses. Kallen (1998), por seu lado, afirmava que cada homem e mulher participa de um grupo étnico maior, baseado numa linha de ancestralidade e em padrões sociais e culturais 
institucionalizados. Para Croly e Kallen, portanto, a inserção social de cada indivíduo deveria ser mediada por seu grupo profissional ou étnico, sob risco do acirramento do conflito social e do melting-pot.

O tema da relação entre indivíduo, grupo, comunidade e outras formas de configuração social não se restringiam, evidentemente, aos Estados Unidos da Era Progressista. Estão no coração do nascimento da própria sociologia e do pluralismo norte-americano. Com Kallen, ele adquiriu contornos próprios, com a aplicação do conceito de pluralismo cultural à ideia de nação norte-americana. E, nesse sentido específico, os judeus dos Estados Unidos constituíam caso particular.

\section{Pluralismo cultural, liberalismo e sionismo}

A América não é Galut. Foi dessa forma que Rebecca Samuels, de Petersburg, Virginia, explicou em carta aos pais alemães, em fins do século XVIII, a experiência de viver nos Estados Unidos (LIPSET; RAAB, 1995, p. 44).

Não que não houvesse preconceito antijudaico ou antissemitismo nos Estados Unidos, então ou depois. Nas primeiras décadas do século XX, judeus com frequência eram associados ora a banqueiros, ora a radicais, e diversas universidades impunham barreiras à sua entrada como professores ou alunos. Nos Estados Unidos, no entanto, os judeus não tiveram que se emancipar de estruturas de Antigo Regime. Na terra do Jim Crow, John Higham (1966, p. 243) chegou a afirmar não haver propriamente uma Questão Judaica, ainda que David Sorkin (2010, p. 176) aponte que no século XIX legislações estaduais restringissem direitos de judeus. De modo geral, no entanto, os judeus dos Estados Unidos emanciparam-se ao se dirigirem a uma sociedade que desde sua fundação era marcada pelo pluralismo religioso e pela laicidade do Estado. A competição entre várias denominações cristãs, ademais, permitiu aos judeus serem mais um, e não o principal, grupo desviante (KATZNELSON, 2001; LIPSET; RAAB, 1995; SARNA, 2004).

Foi essa maior abertura, se comparada à sua experiência europeia, que sentiram os cerca de duzentos e cinquenta mil judeus de língua alemã que 
A imaginação nacional dos judeus norte-americanos: do pluralismo cultural liberal e sionista de Horace Kallen às incertezas do século XXI

Flávio Limoncic

chegaram aos Estados Unidos após 1830. Não que não tenham enfrentado tensões, mas tais judeus entraram para a Universidade, ascenderam às classes médias profissionais e formaram a elite da comunidade judaica norte-americana (somente a partir da década de 1880 teriam início a grande migração de judeus do leste europeu, o recrudescimento do antissemitismo e barreiras universitárias e outras). Constituíram, também, a base da Reforma norte-americana, que rejeitava tanto a solução messiânica dos diversos ramos da ortodoxia judaica quanto a sionista para a questão da Galut (COHEN, 1984). A rigor, para os reformistas, a Galut sequer estava colocada. A Plataforma de Pittsburgh (1885 apud SARNA, 2004, p. 149), de 1885, documento fundante da Reforma nos Estados Unidos, afirmava: "Não nos consideramos uma nação, mas uma comunidade religiosa e, portanto, não esperamos um retorno para a Palestina, [...] tampouco a restauração de nenhuma lei concernente ao Estado Judaico".

Para Kallen, o antissemitismo em terras norte-americanas advinha não da moderna questão nacional, como no diagnóstico europeu de Herzl, mas da ideia religiosa de missão para o mundo atribuída pelo Pacto aos judeus: se o mundo moderno produziu o princípio da igualdade, a ideia de missão colocava os judeus à parte do mundo moderno. Rejeitando a ideia de Pacto, restava a Kallen a tarefa de definir o fundamento da existência dos judeus. Ainda que pouco claro do ponto de vista conceitual - ora se referia a eles como raça, ora como povo, ora como nação, ora como etnia, ora como nação étnica - Kallen (1932) identificou tal fundamento no hebraísmo, entendido como o conjunto da experiência histórica dos judeus (assim como o helenismo conteria o universo da experiência histórica dos gregos, para além da relação entre gregos e seus deuses). E, nos hebreus, Kallen enxergava convergências com os norte-americanos. Barrett Wendell, professor de literatura em Harvard, chamara sua atenção para o fato de que o espírito de justiça social dos Profetas de Israel havia inspirado os Pais Fundadores da América. Graças a Wendell, Kallen se convenceu de que ser judeu - na concepção hebraísta - não era incompatível com ser ianque. Mais: ao contrário da visão estática de mundo dos helenos, a própria religião judaica teria afinidades com a visão de mundo pragmática norte-americana como 
A imaginação nacional dos judeus norte-americanos: do pluralismo cultural liberal e sionista de Horace Kallen às incertezas do século XXI

Flávio Limoncic

permanente fluxo e mudança, e como passível de aperfeiçoamento e conhecimento científico (MENAND, 2001; RAIDER, 1998; SCHMIDT, 1995):

porque o moralismo [judaico] é positivo, social e ativo, ao contrário do salvacionismo [cristão], que é negativo, privado e passivo, Judaísmo traz consigo uma alegria de viver que os rabinos chamavam de "alegria da Lei". O Judaísmo, consequentemente, como uma tradição ética e corporativa, não tem conflito com a visão da existência humana conforme definida pela ciência. (KALLEN, 1932, p. 9, grifos do autor)

Se a Galut não se aplicava aos Estados Unidos e havia uma convergência entre hebreus e norte-americanos, a Grande Guerra ampliava para os judeus a ameaça do melting-pot. enquanto germano-americanos eram pró-Alemanha e anglo-americanos eram pró-Inglaterra, os judeus, embora em sua maioria de origem russa, apoiavam a Alemanha, posto que na Rússia haviam sido oprimidos e aterrorizados pelo regime czarista. Para Kallen $(1915,1998)$, isso se devia ao fato de que os judeus norte-americanos não possuíam um centro espiritual e cultural, um old country, que lhes servisse de diapasão para afinar seus instrumentos na sinfonia nacional norte-americana. É nesse ponto que Kallen se aproxima do sionismo, mas o faz por vias mais próximas as de Ahad Ha'am do que a de Herzl: a Palestina deveria servir aos judeus não como refúgio do antissemitismo, mas como o centro espiritual e cultural. Fiel ao pluralismo cultural, Kallen chegou a afirmar que apoiar a presença judaica na Palestina faria dos judeus melhores norte-americanos.

A seu ver, a presença judaica na Palestina faria parte da resolução do problema de várias minorias no pós-Guerra: a completa restauração da Bélgica; a desanexação da Alsácia-Lorena; a federalização dos Bálcãs, segundo critérios de unidade política e autonomia cultural; autodeterminação de poloneses, tcheco-eslovacos e iugoslavos... Chegou mesmo a defender os Estados Unidos da Ásia Menor, envolvendo judeus, árabes e armênios. O paralelo com a sinfonia norte-americana é evidente, assim como a inspiração suiça, onde franceses e alemães étnicos viviam em paz, enquanto cidadãos franceses e alemães se matavam na Grande Guerra (KALLEN, 1918; GREENE, 2006; PIANKO, 2008; SCHMIDT, 1995). 
A imaginação nacional dos judeus norte-americanos: do pluralismo cultural liberal e sionista de Horace Kallen às incertezas do século XXI

O que não variou no pensamento de Kallen foi a defesa de que a presença judaica na Palestina deveria ser fortemente inspirada no liberalismo norteamericano da Era Progressista. Para tal, ele não hesitou em buscar o apoio de Louis Brandeis, em 1912. Nascido em 1856, em Louisville, Kentucky, filho, ele também, da elite judaica norte-americana de fala alemã - seus pais eram imigrantes da Boêmia -, Brandeis formou-se em direito em Harvard e, por sua militância contra as grandes corporações e pelos direitos dos trabalhadores, notabilizou-se como o advogado do povo. Tão associado estava ao liberalismo progressista que sequer sua aproximação com o sionismo impediu que o presidente Woodrow Wilson o nomeasse Juiz da Suprema Corte dos Estados Unidos, em 1916.

Com Brandeis, caía politicamente por terra o grande temor da elite judaica de origem alemã: de que a adesão ao sionismo resultasse em acusações de dupla lealdade. Jacob Schiff, talvez o mais conhecido membro de tal elite, recusou-se a sequer encontrar Theodor Herzl, argumentando: "Sou pura e simplesmente um americano e não posso pertencer a duas nações" (SCHIFF, 1905 apud WISE, 1948, p. 33). Não deve causar surpresa, pois, que, em 1908, quando a influência alemã não havia ainda sucumbido à crescente força política da imigração do leste europeu, a Federation of American Zionists reunisse apenas 12 mil membros (AMERICAN JEWISH YEAR BOOK, 1915, p. 339).

Ressoando a associação de Kallen entre América, judeus, pluralismo, liberalismo e sionismo, Brandeis afirmou:

Os Judeus deram ao mundo as três grandes religiões, a reverência à lei e as mais altas concepções de moralidade. [...] Sob os nomes de democracia e justiça social, nossos ensinamentos de fraternidade e justiça tornaram-se aquilo porque se luta hoje na América e na Europa Ocidental. Nossa concepção de lei está encarnada na Constituição americana, que proclama que o nosso é um "governo de leis, não de homens".

[...] Que nenhum americano imagine que o sionismo seja inconsistente com o Patriotismo. Múltiplas lealdades são censuráveis apenas se forem inconsistentes. Um homem é melhor cidadão dos Estados Unidos ao ser também um cidadão leal de seu estado e de sua cidade [...]. Todo judeu americano que contribua para o assentamento judaico na Palestina, ainda que sinta que ele próprio ou seus descendentes jamais viverão lá, será, também, um homem melhor e um americano melhor. (BRANDEIS, 20--?) 
A imaginação nacional dos judeus norte-americanos: do pluralismo cultural liberal e sionista de Horace Kallen às incertezas do século XXI

Flávio Limoncic

Após a adesão de Brandeis, o sionismo norte-americano incorporou a tal ponto o liberalismo progressista que, em 1918, a Zionist Organization of America aprovou o Programa de Pittsburgh, estabelecendo como sua política a igualdade civil e política dos habitantes da Palestina, independente de raça, sexo ou religião; propriedade e controle públicos dos recursos naturais e da infraestrutura; princípio cooperativo na indústria, agricultura, comércio e finanças; instrução pública e gratuita; hebraico como língua nacional. Elaborado por Kallen, com auxílio de membros do grupo sionista Parushim e revisado por Brandeis, o Programa tornava a presença judaica na Palestina um empreendimento de engenharia social ou, no dizer de Bernard Rosenblatt (1919, p. 10-11), "um laboratório de experimentos momentosos". Em 1921, esse sionismo americanizado tinha tão pouca relação com o sionismo europeu que Chaim Weizmann, que em 1948 viria a ser o primeiro presidente do Estado de Israel, afirmou em princípio dos anos 1920: "Não concordo com a filosofia do seu sionismo. Não há ponte entre Washington e Pinsk" (WEIZMANN, 1920 apud LIPSET; RAAB, 1995, p. 116).

\section{A crise do consenso sionista nos Estados Unidos}

No pós-Segunda Guerra, muitos judeus dos Estados Unidos, informados pelo Jerusalem Post e pela Jewish Telegraphic Agency, alimentaram a imagem de uma Israel liberal e progressista. Outros construíram tal imagem através do filme Exodus, de 1960, western no deserto protagonizado por Paul Newman, antítese judaico-americana do judeu do gueto. Para a maioria, Israel e o sionismo representavam a principal ligação com o mundo judaico. Para usar a expressão de Luiz Salgado Neto (2018), a pequena América no Oriente alimentou em muitos judeus a autoidentificação positiva como grupo étnico norte-americano, um diapasão para afinar o instrumento judaico na sinfonia norte-americana. 0 resultado é o que Jeffrey Shandler (2001) chamou de natureza empresarial do sionismo dos Estados Unidos: "Como produtores teatrais, os sionistas americanos engajaram-se em atividades centradas na arrecadação de fundos e outros arranjos materiais para um empreendimento realizado por outros". Porque, é bom lembrar, quando resolveram sair de Nova York e Chicago, tais 
A imaginação nacional dos judeus norte-americanos: do pluralismo cultural liberal e sionista de Horace Kallen às incertezas do século XXI

Flávio Limoncic

judeus não foram viver em Israel, mas em Miami e Los Angeles (MOORE, 1994; SARNA, 1996).

Para Jonathan Sarna, foi a popularização da internet, pouco depois do início da intifada palestina, em 1987, que propiciou à maioria dos judeus entrar em contato direto com a realidade israelense. Ao fazê-lo, descobriram que o chalutz (pioneiro sionista) não se tornara o liberal e progressista yeoman jeffersoniano e turneriano, como queria Kallen, mas o viril ranger rooseveltiano. Dov Waxman e Hasia Diner, por exemplo, localizam a raiz da erosão do consenso sionista justamente na ocupação militar israelense da Cisjordânia e na ausência de solução para a questão palestina. Para Anita Shapira, a agenda liberal dos judeus dos Estados Unidos também teria entrado em conflito com a realidade israelense no campo dos direitos das mulheres e dos homossexuais, posto que a Reforma, a maior denominação judaica dos Estados Unidos, autoriza a ordenação de rabinas e a realização de casamentos entre pessoas do mesmo sexo, ambas consideradas anátemas pelo judaísmo ortodoxo com grande influência na vida civil dos cidadãos judeus de Israel. ${ }^{2}$ Como quer Daniel Gordis, enfim, os judeus norte-americanos viveriam hoje a tensão entre o universalismo do liberalismo norte-americano e o particularismo nacional judaico, cindindo a articulação entre ambos, realizada por Kallen, e se inclinando pelo primeiro (MOMENT, 2018).

Alguns dados ajudam a ilustrar o cenário. Em 2018, 53\% dos judeus norteamericanos sentiam seus laços com o Estado Israel enfraquecidos pelo reconhecimento oficial do judaísmo ortodoxo, contra $7 \%$ que os sentiam fortalecidos. Em 2019, 59\% nunca haviam visitado Israel. Nas eleições presidenciais de 2012, 65\% dos judeus norte-americanos declararam intenção de voto em Barak Obama, ao passo que 57\% dos judeus israelenses teriam votado no candidato republicano, Mitt Romney. Inversamente, 45\% dos árabes israelenses teriam votado em Obama, contra 15\% em Romney. Em 2016, 27\% dos judeus israelenses afirmavam que lutar por justiça e equidade era parte essencial

\footnotetext{
A ortodoxia é, ela própria, diversa. Nos Estados Unidos, ortodoxos modernos admitem acomodação com a modernidade, ao passo que os chamados haredim vivem em enclaves, sendo alguns, inclusive, antissionistas (GUROCK, 2009; HEILMAN, 2006; INBARI, 2010; KERENKRATZ, 2018).
} 
de sua identidade judaica, contra 56\% dos judeus norte-americanos. Em 2018 depois, portanto, do reconhecimento norte-americano de Jerusalém como capital de Israel -, 61\% dos judeus norte-americanos desaprovavam a forma como Donald Trump conduzia as relações Estados Unidos-Israel, ao passo que $77 \%$ dos judeus israelenses as apoiavam. Mesmo no campo do riso, judeus norteamericanos e judeus israelenses divergem: para $42 \%$ dos primeiros, ter senso de humor é parte de sua identidade judaica, contra 9\% dos segundos. Não chega a surpreender, portanto, que entre 2000 e 2019 a concordância com a frase "Caring about Israel is a very important part of my being a Jew' tenha caído de $80 \%$ para $62 \%$ dos judeus norte-americanos, ao passo que a discordância subiu de 18\% para 35\% (AMERICAN-ISRAELI COOPERATIVE ENTERPRISE, c2020b; AMERICAN JEWISH COMMITEE, 2018b; FRIEDMAN, 2012; LIPKA, 2016; SHESKIN; DASHEFSKY, 2010).

\section{O século XXI}

Em princípios do século XXI, os judeus permanecem liberais e o consenso sionista erode, mas mudanças demográficas, políticas e culturais podem alterar o cenário. Uma delas é a própria reconfiguração do liberalismo. Há mais de 30 anos, Gerstle e Fraser (1989) apontavam que a eleição de Ronald Reagan, em 1980, marcava o fim da Ordem do New Deal, cujo último suspiro foi a Grande Sociedade de Lyndon Johnson. Pouco depois, Alan Brinkley (1995) também fez referência ao ocaso da era da reforma liberal. Foi essa Ordem, justamente, que, nas palavras de Marshall Berman (1987), aqueceu os judeus norte-americanos. Não à toa, dois importantes intelectuais judeus, Paul Krugman (2007) e Eric Alterman (2008), preconizam, não sem nostalgia, a volta do liberalismo de Franklin D. Roosevelt. O segundo, em particular, lamenta a derivação do liberalismo centrado em políticas redistributivas, tão caras ao New Deal, para a luta identitária.

Se o liberalismo se reconfigura, Lipset e Raab (1995) sugerem que a força integradora da sociedade norte-americana aponta para um futuro judaico nos Estados Unidos mais próximo ao melting-pot de Zangwill do que ao pluralismo cultural de Kallen, com a consequente redução numérica da comunidade judaica 
A imaginação nacional dos judeus norte-americanos: do pluralismo cultural liberal e sionista de Horace Kallen às incertezas do século XXI

Flávio Limoncic

e uma definição mais religiosa do que étnica de sua identidade. Edieal Pinker (202-?), pelo contrário, a partir de dados de 2013, projeta um crescimento do número de judeus sustentado por altas taxas de fertilidade de casais ortodoxos. Calcula ele que, em 50 anos, ortodoxos passarão dos atuais 13\% para 28\% dos judeus dos Estados Unidos, ao passo que a participação de conservadores e reformistas cairá 47\%. Se o mundo ortodoxo vive em um regime de historicidade que projeta como horizonte de expectativa o advento da Era Messiânica, um desdobramento de tal tendência seria um crescente conservadorismo político por parte dos judeus dos Estados Unidos. No campo dos comportamentos, por exemplo, os códigos morais do universo ortodoxo são baseados nas Escrituras, não nos valores modernos, que enfatizam a realização pessoal. (FELDMAN; ADKINS, 2018; SALES; ADKINS, 2020)

É possível, também, que a erosão do consenso sionista leve os cerca de 2 milhões de judeus dos Estados Unidos sem denominação religiosa a novos estilos de imaginação comunitária associados ao old country europeu. A rigor, tal tipo de imaginação nunca deixou de existir. Partituras de doinas romenas foram publicadas em Nova York ao longo de todo o século XX e músicas como Rumania, Rumania e My Yiddish Momme fortaleceram os vínculos sentimentais dos judeus com o ídiche e a Europa Oriental. Em 1971, no auge do consenso sionista, o filme Um violinista no telhado, versão americanizada da vida judaica num shtetl (aldeia) da Europa Oriental, fez enorme sucesso.

Desde a década de 1970, a música klezmer vem se tornando popular em cerimônias de casamento e bar mitzvah. Por outro lado, a herança sefardita também tem sido recuperada. Até os anos 1980, os temas prevalecentes da literatura produzida pelos judeus eram o universo do shtelt e a vida nos próprios Estados Unidos, sendo Isaac Bashevis Singer, Saul Bellow e Philip Roth algumas de suas maiores expressões. Esse, aliás, o universo de Woody Allen, que, como os intelectuais de Nova York (Hannah Arendt, o próprio Bellow, Nathan Glazer, Richard Hofstadter, Seymour Martin Lipset, Susan Sontag, Lionel Trilling, Irving Howe, dentre outros) não se notabilizou pelo sionismo. Em seu amplo balanço das questões políticas e estéticas em que tais intelectuais se envolveram, Howe (1969) sequer faz referências a Israel ou ao sionismo (GITTELMAN, 1978; 
A imaginação nacional dos judeus norte-americanos: do pluralismo cultural liberal e sionista de Horace Kallen às incertezas do século XXI

Flávio Limoncic

KIRSHENBLATT-GIMBLETT, 2001; MOORE, 1994; PARELES, 1996; SLOBIN, 1984; SOKOLOFF, 1998; WOLITZ, 1988).

A área acadêmica de Estudos Judaicos reflete tais transformações. Nos dias de hoje, ela enfatiza mais a interpenetração dos mundos judaico e não judaico do que a especificidade judaica, assim como a circulação das culturas judaicas para além das fronteiras de nações, Estados-Nação e Impérios. Não à toa, Israel tem sido pensado a partir de seu lugar na moldura dos estudos sobre colonialismo e nacionalismo (MOORE, 2015).

Em suma, se o liberalismo não é mais o mesmo, tampouco os judeus norte-americanos o são. Se desaparecerão no melting-pot, se ortodoxos dominarão a vida judaica dos Estados Unidos, se um estilo de imaginação comunitária idichista ou sefardita vier a se fortalecer ao lado da ortodoxa, se a dimensão liberal do sionismo judaico derivará para posições mais próximas às do neoconservadorismo, do evangelismo branco e do Partido Republicano, nada disso há como saber. O que parece claro é que o timbre judaico norte-americano soa hoje mais dissonante do que Kallen poderia supor.

\section{Referências}

ALTERMAN, Eric. Why we're liberals: a political handbook for post-Bush America. New York: Viking Adult, 2008.

AMERICAN-ISRAELI COOPERATIVE ENTERPRISE. Jewish Members of U.S. Congress: 114th Congress. [S.l.]: AICE, c2020a. Disponível em: http://www.jewishvirtuallibrary.org/jewish-members-of-the-114th-congress. Acesso em: 4 nov. 2017.

AMERICAN-ISRAELI COOPERATIVE ENTERPRISE. AJC Surveys of American Jewish Opinion (1993-2019). [S.l.]: AICE, c2020b. Disponível em: https://www.jewishvirtuallibrary.org/ajc-surveys-of-american-jewishopinion\#jewid. Acesso em: 30 nov. 2019.

AMERICAN JEWISH COMMITEE. AJC 2013 Survey of American Jewish Opinion. [S.l.]: AJC, 2013. Disponível em: https://www.ajc.org/news/ajc-2013-survey-ofamerican-jewish-opinion. Acesso em: 9 jul. 2016. 
AMERICAN JEWISH COMMITEE. AJC Survey of American Jewish Opinion 2016. [S.l.]: AJC, 2016. Disponível em: https://www.ajc.org/news/ajc-survey-ofamerican-jewish-opinion-2016. Acesso em: 9 jul. 2016.

AMERICAN JEWISH COMMITEE. AJC 2018 Survey of American and Israeli Jewish Opinion. [S.l.]: AJC, 2018a. Disponível em: https://www.ajc.org/survey2018. Acesso em: 1 nov. 2018.

AMERICAN JEWISH COMMITEE. AJC Comparative Surveys of Israeli, U.S. JewS Show Some Serious Divisions. Global Voice. Jerusalem, 10 June 2018b. Disponível em: https://www.ajc.org/news/ajc-comparative-surveys-of-israelius-jews-show-some-serious-divisions. Acesso em: 8 ago. 2018.

AMERICAN JEWISH COMMITEE. AJC 2019 Survey of American Jews on Antisemitism in America. [S.l.]: AJC, 2019. Disponivel em: https://www.ajc.org/AntisemitismSurvey2019. Acesso em: 4 nov. 2019.

AMERICAN JEWISH YEAR BOOK. Philadelphia: Jewish Publication Society of America, v. 16, 8 Sept. 1915.

ANDERSON, Benedict. Comunidades imaginadas. São Paulo: Companhia das Letras, 2008.

BAUMAN, Zygmunt. Exit visas and entry tickets: paradoxes of Jewish assimilation. Telos: critical theory of the contemporary, [s.l.], v. 1988, n. 77, p. 4577, 21 Sept. 1988.

BERGER, Joseph. Milton Himmelfarb, wry essayst, 87, dies. The New York Times, New York, 15 Jan. 2006.

BERMAN, Marshall. Tudo que é sólido desmancha no ar. São Paulo: Companhia das Letras, 1987.

BOAS, Franz. Race problems in America. Science, [s.l.], v. 29, n. 752, p. 839-849, 28 May 1909.

BRANDEIS, Louis. The jewish problem: how to solve it: speech to the conference of Eastern council of reform rabbis, April 25, 1915. [S.L.]: Louis D. Brandeis School of Law Library, [20--?]. Disponível em:

https://louisville.edu/law/library/special-collections/the-louis-d.-brandeiscollection/the-jewish-problem-how-to-solve-it-by-louis-d.-brandeis. Acesso em: 22 jan. 2021. 
A imaginação nacional dos judeus norte-americanos: do pluralismo cultural liberal e sionista de Horace Kallen às incertezas do século XXI

BRINKLEY, Alan. The end of reform: new deal liberalism in recession and war. New York: Vintage Books, 1995.

COHEN, Naomi. Encounter with emancipation: the german jews in the United States, 1830-1914. Philadelphia: Jewish Publication Society of America, 1984.

COHEN, Steven. Ties and tensions: the 1986 survey of American Jewish attitudes toward Israel and Israelis. New York: American Jewish Committee, 1986.

COHEN, Steven. Dimensions of american jewish liberalism. New York: American Jewish Committee, 1989.

CROLY, Herbert. The promise of american life. Boston: Northeastern University Press, 1989. Original de 1909.

DAHL, Robert. És democrática la constitución americana? Buenos Aires: Fondo de Cultura Económica de Argentina, 2003.

ELIAS, Norbert; SCOTSON, John. Os outsiders e os estabelecidos: sociologia das relações de poder a partir de uma pequena comunidade. Rio de Janeiro: Jorge Zahar Editor, 2000.

FELDMAN, Ari; ADKINS, Laura E. Orthodox to dominate american jewry coming decades as population booms. Forward. [S.l.], 12 June 2018. Disponível em: https://forward.com/news/402663/orthodox-will-dominate-american-jewry-incoming-decades-as-population/. Acesso em: 30 nov. 2019.

FRIEDMAN, Uri. New poll: Israeli Jews prefer Romney by large margin. Foreign Policy, [s.l.], 28 Oct. 2012. Disponível em:

https://foreignpolicy.com/2012/10/28/new-poll-israeli-jews-prefer-romney-bylarge-margin/. Acesso em: 13 out. 2013.

FUCHS, Lawrence. Political behavior of American Jews. Westport: Praeger Publishers, 1980.

GERSTLE, Gary. The Protean character of American liberalism. The American Historical Review, [s.l.], v. 99, n. 4, p. 1043-1073, Oct. 1994.

GERSTLE, Gary. American crucible: race and nation in the twentieth century. Princeton: Princeton University Press, 2011.

GERSTLE, Gary; FRASER, Steve. The rise and fall of the new deal order. Princeton: Princeton University Press, 1989. 
A imaginação nacional dos judeus norte-americanos: do pluralismo cultural liberal e sionista de Horace Kallen às incertezas do século XXI

GINSBERG, Benjamin. The fatal embrace: jews and the state. Chicago: University of Chicago Press, 1993.

GITELMAN, Zvi. The emergence of modern Jewish politics: Bundism and Zionism in Eastern Europe. Pittsburgh: University of Pittsburgh Press, 2003.

GITTELMAN, Sol. From shtetl to suburbia: the family in jewish literary imagination. Boston: Beacon Press, 1978.

GOTTFRIED, Paul. Paul Gottfried: Don't call me the 'godfather' of those alt-right neo-Nazis. I'm jewish. National Post, Toronto, 17 Apr. 2018. Disponível em: https://nationalpost.com/opinion/paul-gottfried-dont-call-me-the-godfatherof-those-alt-right-neo-nazis-im-jewish. Acesso em: 12 fev. 2021.

GREENE, Daniel. A chosen people in a pluralist nation: Horace Kallen and the jewish-american experience. Religion and American Culture: A Journal of Interpretation, [s.l.], v. 16, n. 2, p. 161-193, Summer 2006.

GUARDINO, Peter. The dead march: a history of the mexican-american war. Cambridge: Harvard University Press, 2017.

GUROCK, Jeffrey. Orthodox jews in America. Bloomington: Indiana University Press, 2009.

HARTOG, François. Hacia una nueva condición histórica. Letras Históricas, [s.l.], n. 16, p. 19-34, Primavera/Verano 2017.

HEILMAN, Samuel. Sliding to the right: the contest for the future of american jewish orthodoxy. Berkeley: University of California Press, 2006.

HERBERG, Will. Protestant, catholic, jew. Garden City: Doubleday \& Company, 1960.

HERZL, Theodor. A jewish state: an attempt at a modern solution of the jewish question. New York: Maccabean Publishing Co., 1904.

HIGHAM, John. Strangers in the land: patterns of american nativism, 1860-1925. New York: Atheneum, 1965.

HIGHAM, John. American anti-semitism historically reconsidered. In: STEMBER, Charles (org.). Jews and the american mind. New York: Basic Books, 1966.

HOWE, Irving. The New York intellectuals. Dissent Magazine, [s.l.], 1 Oct. 1969. 
A imaginação nacional dos judeus norte-americanos: do pluralismo cultural liberal e sionista de Horace Kallen às incertezas do século XXI

Disponível em: https://www.dissentmagazine.org/online_articles/irving-howevoice-still-heard-new-york-intellectuals. Acesso em: 13 fev. 2021.

HOWE, Irving. World of our fathers: the journey of the East European jews to America and the life they found and made. New York: Open Road, 2006.

INBARI, Motti. Rabbi Amram Blau Founder of the Neturei Karta Movement: an abridged biography. Hebrew Union College Annual, [s.l.], v. 81, p. 193-232, 2010.

JACOBSON, Mattew Frye. Whiteness of a different color: european immigrants and the alchemy of race. Cambridge: Harvard University Press, 1998.

KALLEN, Horace. Nationality and the hyphenated american. The Menorah Journal, [s.l.], v. 1, n. 2, p. 79-80, Apr. 1915.

KALLEN, Horace. The structure of lasting peace: an inquiry into the motives of war and peace. Boston: Marshall Jones Company, 1918.

KALLEN, Horace. Judaism at bay: toward the adjustment of judaism to modernity. New York: Bloch, 1932.

KALLEN, Horace. Culture and democracy in the United States. New Brunswick: Transaction Publishers, 1998.

KATZNELSON, Ira. Strangers no longer: jews and postwar american political culture. In: MOORE, Deborah Dash; TROEN, Ilan (org.). Divergent jewish cultures: Israel \& America. New Haven: Yale University Press, 2001, p. 304-318.

KEREN-KRATZ, Menachem. Is the jewish state the ultimate evil or a golden opportunity? ideology vs. politics in the teachings and actions of Rabbi Yoel Teitelbaum - the Satmar Rebbe. Jewish Political Studies Review, [s.l.], v. 29, n. 1/2, p. 5-26, 2018.

KIRSHENBLATT-GIMBLETT, Barbara. Imagining Europe: the popular arts of American Jewish ethnography. In: MOORE, Deborah Dash; TROEN, Ilan (org.). Divergent jewish cultures: Israel \& America. New Haven: Yale University Press, 2001. p. 155-191.

KOHN, Hans. The Idea of nationalism. New York: Macmillan Company, 1961.

KOSELLECK, Reinhart. Futuro passado: contribuição à semântica dos tempos históricos. Rio de Janeiro: Contraponto, 2015. 
A imaginação nacional dos judeus norte-americanos: do pluralismo cultural liberal e sionista de Horace Kallen às incertezas do século XXI

KRUGMAN, Paul. The conscience of a liberal. New York: W.W. Norton \& Co., 2007.

LIEBMAN, Charles. The ambivalent American Jew: politics, religion, and Family in American Jewish life. Philadelphia: Jewish Publication Society, 1973.

LIMONCIC, Flávio. Liberalismo e contratação do trabalho nos Estados Unidos da Era Progressista. In: LIMONCIC, Flávio; MARTINHO, Francisco Carlos Palomanes (org.). Os intelectuais do antiliberalismo: projetos e políticas para outras modernidades. Rio de Janeiro: Editora Civilização Brasileira, 2010. p. 501-528.

LIPKA, Michael. A closer look at jewish identity in Israel and the U.S. Pew Research Center. [S.l.], 16 Mar. 2016. Disponivel em:

https://www.pewresearch.org/fact-tank/2016/03/16/a-closer-look-at-jewishidentity-in-israel-and-the-u-s/. Acesso em: 19 nov. 2017.

LIPSET, Seymour Martin; RAAB, Earl. Jews and the new american scene. Cambridge: Harvard University Press, 1995.

MARKET FACTS. 1995 AJC: american jewish attitudes towards Israel and the peace process. New York: The Jewish Federations of North America, 1995. Disponível em: https://www.jewishdatabank.org/databank/searchresults/study/523. Acesso em: 9 jul. 2018.

MEARSHEIMER, John; WALT, Stephen. The Israeli lobby and U.S. foreign policy. New York: Farrar, Strauss and Giroux, 2007.

MENAND, Louis. The metaphysical club: a story of ideas in America. New York: Farrar, Strauss and Giroux, 2001.

MENDES-FLOHR, Paul. German jews: a dual identity. New Haven: Yale University Press, 1999.

MINCZELES, Henri. Histoire générale du Bund: un mouvement révolutionnaire juif. Paris: Éditions Austral, 1995.

MOMENT. The growing gap between Israel and American Jews. Moment. [S.l.], 21 Aug. 2018. Disponível em: https://www.momentmag.com/growing-gap-israelamerican-jews/. Acesso em: 10 jul. 2017.

MOORE, Deborah Dash. At home in America: second generation New York jews. New York: Columbia University Press, 1981.

MOORE, Deborah Dash. To the golden cities: pursuing the american jewish dream in Miami and L.A. Cambridge: Harvard University Press, 1994. 
A imaginação nacional dos judeus norte-americanos: do pluralismo cultural liberal e sionista de Horace Kallen às incertezas do século XXI

MOORE, Deborah Dash. Estudos Judaicos nas Américas: entrevista com Deborah Dash Moore. [Entrevista cedida a] Flávio Limoncic. Revista Digital do NIEJ, [s.l.], ano 5, n. 9, p. 3-5, 2015. Disponível em:

https://niej.files.wordpress.com/2016/07/02-entrevistaddm.pdf. Acesso em: 15 fev. 2021.

NORDAU, Max. The conventional lies of our civilization. Chicago: L. Shick, 1884.

PARELES, Jon. MUSIC REVIEW: a classicist romps in a revival of Klezmer. The New York Times, New York, p. 15, 4 July 1996. Section C. Disponível em: https://www.nytimes.com/1996/07/04/arts/music-review-a-classicist-rompsin-a-revival-of-klezmer.html. Acesso em: 19 nov. 2019.

PIANKO, Noam. The true liberalism of Zionism: Horace Kallen, jewish nationalism, and the limits of american pluralism. American Jewish History, [s.l.], v. 94, n. 4, p. 299-329, Dec. 2008.

PIERUCCI, Antônio Flávio. O desencantamento do mundo: todos os passos do conceito em Max Weber. São Paulo: USP: 34 Letras, 2013.

PINKER, Edieal. Projecting future Jewish demographics in the United States: whither the jews? Yale School of Management, [s.l.], [202-?]. Disponivel em: https://som.yale.edu/sites/default/files/WorkingPaperUSJewishDemographics.pdf. Acesso em: 15 fev. 2021. Working paper.

RAIDER, Mark. The emergence of American Zionism. New York: New York University Press, 1998.

RAND, Ayn. The fountainhead. New York: Boobs-Merrill Company, 1943.

RAND, Ayn. Atlas shrugged. New York: Random House, 1957.

ROSENBLATT, Bernard. Social Zionism (selected essays). Chicago: Public Publishing Company, 1919.

ROSENTHAL, Steven. Irreconcilable diferences?: the waning of the american jewish love affair with Israel. Hanover: Brandeis University Press, 2001.

ROOSEVELT, Theodore. The winning of the west. New York: G. P. Putnam's Sons, 1900.

ROTH, Joseph. Judeus Errantes. Belo Horizonte: Editora Âyiné, 2016. 
A imaginação nacional dos judeus norte-americanos: do pluralismo cultural liberal e sionista de Horace Kallen às incertezas do século XXI

SAID, Edward. Cultura e política. São Paulo: Boitempo Editorial, 2003.

SALES, Ben; ADKINS, Laura. "I think it's Israel": how orthodox jews became republicans. Jewish Telegraphic Agency. New York, 3 Feb. 2020. Disponível em: https://www.jta.org/2020/02/03/politics/i-think-its-israel-how-orthodox-jewsbecame-republicans. Acesso em: 10 fev. 2020.

SALGADO NETO, Luiz. Uma pequena América no Oriente: fundamentos culturais do apoio ao sionismo nos Estados Unidos (1936-1948). Rio de Janeiro: Multifoco, 2018.

SAND, Shlomo. The invention of the jewish people. London: Verso, 2009.

SARNA, Jonathan. A projection of America as it ought to be: Zion in the mind's eye of American Jews. In: GAL, Allon (org.). Envisioning Israel: the changing ideas and images of Jerusalem. Detroit: Wayne State University Press, 1996.

SARNA, Jonathan. American jewish political conservatism in historical perspective. American Jewish History, [s.l.], v. 87, n. 2/3, p. 113-122, June/Sept. 1999.

SARNA, Jonathan. American judaism: a history. New Haven: Yale University Press, 2004.

SARNA, Jonathan; MENDELSOHN, Adam (ed.). Jews and the civil war: a reader. New York: New York University Press, 2010.

SCHMIDT, Sarah. Horace Kallen: prophet of American Zionism. New York: Carlson Publishing, 1995.

SHANDLER, Jeffrey. Producing the future: the impresario culture of American Zionism before 1948. In: MOORE, Deborah Dash; TROEN, Ilan (org.). Divergent Jewish cultures: Israel \& America. New Haven: Yale University Press, 2001, p. 5371.

SHESKIN, Ira; DASHEFSKY, Arnold. Jewish population in the United States, 2010. Storrs: Mandell L. Berman Institute, 2010. Disponível em:

https://www.brandeis.edu/cmjs/conferences/demographyconf/pdfs/Dashefsky_ JewishPopulationUS2010.pdf. Acesso em: 19 nov. 2017.

SLOBIN, Mark. Klezmer music: an American ethnic genre. Yearbook of traditional music, [s.l.], v. 16, p. 34-41, 1984. 
SMITH, Anthony. Chosen peoples: sacred sources of national identity. Oxford: Oxford Univeristy Press, 2003. cap. 3 e 4.

SOKOLOFF, Naomi. Israel and America: cross-cultural encouters and literary imagination. Shofar, [s.l.], v. 16, n. 2, p. 1, Winter 1998.

SORKIN, David. Is American jewry exceptional?: comparing Jewish emancipation in Europe and America. American Jewish History, [s.l.], v. 96, n. 3, p. 175-200, Sept. 2010.

TARCOV, Nathan. Leo Strauss and American conservative thought and politics. Nomos, [s.l.], v. 56, p. 381, 2016.

TURNER, Frederick Jackson. The frontier in American history. New York: Holt, Rinehart and Winston, 1962.

WISE, Stephen. Challenging years. New York: Putnam's Sons, 1948.

WOLITZ, Seth. The americanization of Tevye or boarding the jewish "Mayflower". American Quarterly, v. 40, n. 4, p. 514-536, Dec. 1988.

ZANGWILL, Israel. The melting-pot: drama in four acts. New York: Macmillan Company, 1919. 